\title{
Business Cycle Synchronization in Croatia
}

Zdravko Šergo , Amorino Poropat , Jasmina Gržinić *

Abstract:

The purpose of this paper is to analyze business cycle synchronization in the Croatian economy using various annualized growth rate variables over a period of eighteen years (1992-2010), de-trended by a Hodrick-Prescott filter, and following the Harding and Pagan methodological procedure in the determination of its turning points. Our conceptual analysis of synchronization is based on the technique of concordance indexes and correlation coefficients obtained by the HAC estimators. The main result of the research shows that there is a high degree of probability that dismissal of employees in the Croatian economy will coincide with the contraction phase in industry. The cyclic phase of growth in job creation in great measure coincides with the cyclic phase of growth in exports and the construction sector, as well as with tourist arrivals. There is an almost perfect synchronization between the cyclic phases of the construction sector and imports. The central conclusion of the paper is that this study can establish stylized facts about the dynamics of Croatian business cycles.

Keywords: business cycles, synchronization of business cycles, Croatia

JEL: E32, E 22

DOI: $10.2478 / v 10033-012-0003-9$

\section{Introduction}

The theme of turning point dating and research into the synchronization of business cycles, the comovements of two cycles by a method of concordance indexes, and the calculation of correlation coefficients in the manner the authors conducted in this study on the case of Croatia is a widely exploited research field in the modern analysis of business cycles. Methodologically, our study leans on the research program of concordance index calculations by the authors hereafter.

Various aspects of economic complexity today in Croatia (as a Mediterranean country) deal with different but dependent economic parts such as tourism, labor, monetary flows and production ingredients which will be presented and examined in this paper. It should also be noted that understanding the cyclical characteristics in Croatia's economic activities in a systematic way could be important for the purposes of planning, coordinating and resource allocation in the economy of Croatia.
This paper applies a nonparametric procedure to estimate the concordance index for the assumed variable and studies its cyclical features in relation to the reference variable. In other words, our working assumption is: in Croatia's economy some fields of economic complexity are more interdependent and hence more synchronized

\section{* Zdravko Šergo}

Institute of Agriculture and Tourism, Poreč, Croatia E-mail:zdravko@iptpo.hr

\section{Amorino Poropat}

Institute of Agriculture and Tourism, Poreč, Croatia E-mail: amorino@iptpo.hr

\section{Jasmina Gržinić}

University Jurja Dobrile in Pula, Department of economics and tourism "Dr. Mijo Mirković" Pula E-mail: jasmina.grzinic@efpu.hr 
than others. We do not, however, know a priori the direction or strength of synchronizations among cycles of two opposite variables. In some way our approach is nontheoretical, where first a fact is focused upon, followed by theoretical speculation based on the derived empirical fact. However, the empirical fact should pass regression significance testing. Again, in this context, the word 'nontheoretical' does not refer to something being 'missing'; but rather that something can be shown to be false by testing the various cycles emanating from a "black box economy". In order to characterize business cycle fluctuations and its synchronizations based on our macroeconomic time series, we use correlation coefficients of the cyclical component of each series, with the cyclical component of the reference variable. If these correlation coefficients show significance in the regressions, that (yet true) evidence should hopefully lead us to important stylized facts about business cycle dynamics in Croatia.

The paper is organized as follows: after the Introduction, we select 15 variables stretching from tourism and labor issues to production and monetary flows in Section II. Section III as the main part of this paper studies the business and growth cycle characteristics of the paired variables, e.g. their synchronization based on its concordance indexes. These include the conventional Harding and Pagan nonparametric approach analyzed by a Bry-Bosh algorithm. The relationship between cycles in the assumed sector and those in the particular part of the economy are also explored by a correlation coefficient obtained as a regression parameter. The last Section IV summarizes the main conclusions of this paper.

\section{Literature Review}

Since Clement Juglar (1862) in the nineteenth century economists have been familiar with a cyclic description of economic activity over time, whereby periods of expansion in economic activity are followed by periods of contraction in what has become known as the business cycle. Burns and Mitchell (1946) formalized this nomenclature and derived a dating method whereby peaks and troughs would separate the phases of the business cycle; and the latter could be analyzed statistically in terms of duration, amplitude and so on. The dating committee of the National Bureau of Economic Research in the USA still follows their lead in defining the turning points of business cycles for that country.
Fifteen years ago Blanchard and Fischer (1989) observed that "most macroeconomists (...) have abandoned the Burns-Mitchell methodology." Blanchard and Fischer (1989) explained this shift in the method by arguing that the Burns-Mitchell approach did not generate statistics with "well-defined statistical properties."

Don Harding and Adrian Pagan (2001) have recently stimulated renewed interest in the Burns Mitchell method with a series of articles in which they demonstrated that the statistical foundations of a dating algorithm can be described formally, and that such algorithms may be attractively robust and practically easy tools for identifying the phases of the cycle.

Zhang and Zhuang (2002) in their paper construct leading indicator systems for the Malaysian and Philippine economies using economic and financial data, with an attempt to predict the turning points of growth cycles in the two countries. The study conducted by Lahiri et al. (2003), underscores the importance of transportation indicators in monitoring cyclical movements in the aggregate economy. The paper by Avouyi-Dovi et al. (2006) provides an analysis of comovements between real and financial variables in three new EU member countries (the Czech Republic, Hungary and Poland) and the Eurozone. Biscarri and Pérez de Gracia (2002) find that cycles in European countries have become substantially more concordant in recent years, a result that was to be expected given the increased integration of European financial markets, but that the degree of concordance is not high.

We did not study the concordance between business and financial cycles in a broader sense and the interactions between their different phases for Croatia, but we should mention some interesting works, because after the financial crises in 2008 this research program has become promising. To provide a broad perspective about financial cycles Stijn Claessens, M. Ayhan Kose and Marco E. Terrones (2011) employ three measures: credit, house and equity prices in their paper. Their paper analyzes the interactions between business and financial cycles using an extensive database of over 200 business and 700 financial cycles in 44 countries for the period 1960-2007. They suggest that there are strong linkages between different phases of business and financial cycles. Bordo and Haubrich (2010) analyze cycles in money, credit and output between 1875 and 2007 in the U.S. They argue that credit disruptions tend to exacerbate cyclical downturns. Claessens, Kose and Terrones (2009) 
analyze the implications of credit crunches and asset price busts for recessions. Gilchrist and Zakrajsek (2009) provide a short review of literature for models presenting channels of transmission between the financial sector and real economy. The seminal work of Reinhart and Rogoff (2009) analyzes the evolution of macroeconomic aggregates around episodes of financial crisis.

We followed Harding and Pagan (2001) in this paper and applied their dating algorithm, improved by Bry and Bosch (1971), to identify the turning points of a heterogeneous set of macro-economic variables and to try in a broader way to determinate business cycles in the Croatian economy.

\section{Conceptual Background}

Our benchmark theoretical consideration about business cycle issues in Croatia's economy emphasizes the interrelatedness of the various sectors of the economy. Hence, disturbances in one part of the economy - for example, labor productivity in the industrial sector can result in symptoms in other parts that seem far removed, such as job vacancy rate or imports.

Where disturbances originate in the system (are they real or nominal shock?) and where the forces that prevent the system from quick and smooth readjustment are when it is disturbed, are not questions within the focus of our research.

The central idea of business-cycle literature that dominated economic schools and that holds that the economy has regular and periodic waves - i.e. cycles, has few adherents today. Both the conservative real-business cycle theory, which emerged from new classical ideas, and the liberal new Keynesians business cycle theory, agree on this issue (for more see: Lutz, 2002). Although they look for the cause of cycles in different sources and directions, these issues are outside the focus of our research.

We do, however, conjecture that there exist seemingly random irregular fluctuations around the growth trends of particular parts of the economy proxied by the cyclical component of time series. Thus, given two snapshots in time, predicting the latter with the earlier is nearly impossible and we do not try to do this. Behind the synchronization of the duration of a discrete event (recession/expansion), and within two particular parts of the economic system there stands mere chance, which we call event congruency, and from which the synchronization of two cycles emanates. For more about the concept of statistic congruency and event synchronization, see Aczel (2004).

A crucial part of the tracing system of business cycles is the computation of the cycles. We select one of the most frequently used cycle extraction methods, or filters: the Hodrick -Prescott filter.

\subsection{Cycle Extraction Method}

We should smooth our time series. We use the Hodrick-Prescott (1981) filter again for trend cycle decompositions. The filter contains only one parameter, which controls the smoothness of the filtered series.

Hodrick and Prescott (1981) use the following model:

$$
y t=\mu t+c t,
$$

According to this model the series contains only a trend and a cycle. The ratio of the variances of $c t$ and $\mu t$ is assumed to be equal to the chosen parameter $\lambda$. For a larger $\lambda$, a smoother trend will be obtained. As a measure of the smoothness of the trend, Hodrick and Prescott (1981) take the sum of squares of the second order differences. Furthermore, they pose that the cycle is the deviation from the trend, and its long-term average should be zero. This results in the following minimization problem:

$\min _{\left(\mu_{t}\right)}\left\{\sum_{t=1}^{T} c_{t}^{2}+\lambda \sum_{t=1}^{T}\left[\left(\mu_{t}-\mu_{t-1}\right)-\left(\mu_{t-1}-\mu_{t-2}\right)\right]^{2}\right\}$

According to the literature, the optimal values are $\lambda$ $=1600$ and $\lambda=14400$ for quarterly and monthly data, respectively. In our computations, we employ $\lambda=1600$, although we are dealing with monthly data frequencies as we have stressed before. There are two reasons for this: first, $\lambda=14400$ implies too smooth a trend line, where it is more difficult to identify the turning points, and second, the time series which are analyzed are, in fact, annual growth rates at a monthly level.

We present the non-linear trends obtained from the application of the HP filter, with $\lambda=1600$, to the monthly growth rate of the included time series in Croatia.

All the time series are given as year-on-year growth rates (YoY). This rate is calculated by dividing the figure $\mathrm{Y}(\mathrm{i}, \mathrm{t})$ for a given period $\mathrm{t}$ ( $\mathrm{a}$ month in relation to the frequency of the data i) by the value of the corresponding 
period in the previous year $Y(i, t-12)$.

For monthly data:

$\mathrm{YoY}(\mathrm{i}, \mathrm{t})=\{[\mathrm{Y}(\mathrm{i}, \mathrm{t}) / \mathrm{Y}(\mathrm{i}, \mathrm{t}-12)]-1\} * 100$

The same result is obtained by the difference of the logged original series.

$\operatorname{YoY}(\mathrm{i}, \mathrm{t})=\Delta \mathrm{yi}, \mathrm{t}=\ln (\mathrm{Yi}, \mathrm{t})-\ln (\mathrm{Yi}, \mathrm{t}-12)$

The non-linear trends highlight the cyclical nature of the series, enabling the identification of peaks and troughs for each case.

\subsection{Dating Method}

The dating algorithm used here is by Bry and Boschan (1971) as suggested by Harding and Pagan (2002) in various recent papers. This algorithm identifies local minima (troughs) and local maxima (peaks) in a single time series, or $\{\Delta y t\}$ after a log transformation. Peaks are found where $\Delta y$ s is larger than $\mathrm{k}$ values of $\{\Delta \mathrm{yt}\}$ in both directions $[\mathrm{t}-\mathrm{k}, \mathrm{t}+\mathrm{k}]$ and troughs where $\Delta \mathrm{ys}$ is smaller than $k$ values of $\{\Delta y t\}$ in both directions. The $k$ value stands for the minimal duration of a phase given in the number of months.

The size of $k$ is set by the censoring rule of the algorithm. There is no optimal size for k, but Bry and Boschan (1971) suggest a value of 5 at a monthly frequency. A censoring rule is also required to ensure that the cycle (and each of its phases) is of a minimum duration. Again we followed Harding and Pagan (2001) and set the minimum duration for a single phase at 9 months and the minimum duration for a complete cycle (from peak-to-peak or trough-to-trough) at 24 months. The Bry-Boschan algorithm therefore identifies turning points according to the requirements in equation 3 and 4, subject to the abovementioned censoring rules.

\section{Peak at $t$ if \\ $\left\{\left(\Delta y_{t-9}, \Delta y_{t-8}, \ldots, \Delta y_{t-2}, \Delta y_{t-1}\right)<\Delta y_{t}>\left(\Delta y_{t+1}, \Delta y_{t+2}, \ldots, \Delta y_{t+8}, \Delta y_{t+9}\right)\right\}$}

Trough at $t$ if

$\left\{\left(\Delta y_{t-9}, \Delta y_{t-8}, \ldots, \Delta y_{t-2}, \Delta y_{t-1}\right)>\Delta y_{t}<\left(\Delta y_{t+1}, \Delta y_{t+2}, \ldots, \Delta y_{t+8}, \Delta y_{t+9}\right)\right\}$
Once the turning points of the cycle have been identified it is possible to describe the characteristics of the cycle in terms of duration, amplitude, steepness, nonlinearity, and synchronization among the two assumed cycles.

In practice, the Bry-Boschan algorithm is supplemented by censoring procedures to distinguish the real peaks and troughs from spurious ones, e.g., a movement from a peak to a trough (phase) cannot be shorter than 9 months and a complete cycle must be at least 24 months long. The resulting turning points define the "specific cycle" of each component series.

\subsection{Turning Point Determination in Relevant Cycles}

The classical approach defines the business cycle directly by analyzing the change in the level of a variable, characterizing the cycle as a succession of expansions and recessions. Formally, an expansion is defined as the period of time separating a trough from a peak; conversely, a recession is the period between a peak and a trough. What is crucial in this approach, then, is to precisely define and identify the turning points, i.e. the peaks and troughs. Using these turning points, a recession (expansion) is defined as the time separating a peak (trough) from a trough (peak).

\subsection{Synchronization and concordance index in growth cycles}

Though it fell out of fashion after the 1970s, this view of the cycle has recently been the subject of several papers, which proposed a simple method for analyzing the concordance between two series, i.e. the simultaneous presence of the two series in the same recessionary or expansionary phase of the cycle. Before compiling the concordance index, we first have to define a function to indicate the phases of increase (or decline), Sy, $t=1$ of a variable, $y$ for example, which we will use to calculate the index: Sy, $t=1$ if $y$ increases at $t$, and 0 otherwise. We use a statistic developed by Harding and Pagan as the concordance index (see Canova:2007).

The concordance index for $x$, written $c x y$, is defined as the average number of periods in which two variables $x$ and $y$ coincide at the same phase of the cycle, i.e.:

$C_{x, y}=\frac{1}{T}=\sum_{t=1}^{T}\left[S_{x, t} S_{y, t}+\left(1-S_{x, t}\right)\left(1-S_{y, t}\right)\right]$ 
The index has a value of 1 if $x$ and $y$ are always in the same phase, i.e. the two series are in perfect concordance, with expansions and contractions perfectly juxtaposed. If the index reads $0, x$ and $y$ are always in opposite phases, i.e. the two series are in perfect discordance, with either a pronounced lag or a total contrast in phase.

\subsection{Synchronization of Cycles Test}

In general, the distributional properties of $C x, y$ is unknown. To calculate the significance levels for these indices, we use the method suggested by Harding and Pagan (2004), which we detail below. Let $\mu_{s, i}$ and $\sigma_{s, i}, i$ $=(x, y)$ denote the empirical mean and the empirical standard deviation of $S_{i, t}$ respectively. If $\rho_{s}$ denotes the empirical correlation between $S x, t$, and $S y, t$, it can be shown that the concordance index is equal to:

$C_{x, y}=1+2 \rho_{s} \sigma_{s_{x}} \sigma_{s_{y}}-\mu_{s_{x}}-\mu_{s_{y}}$

According to this equation, $C x y$ and $\rho$ s are linked in such a way that either of these two statistics can be studied to the same effect. To estimate $\rho$, Harding and Pagan suggest estimating the linear relationship:

$\frac{S_{y, t}}{\sigma_{S_{y}}}=$ const $+\rho_{s}\left(\frac{S_{x, t}}{\sigma_{S_{x}}}\right)+\varepsilon_{t}$

where const is a constant and $\varepsilon t$ a residual. The estimation procedure for equation (9) must be robust to serial correlation in the residuals, because $\varepsilon t$ inherits the serial correlation properties of $S y, t$, under the null hypothesis $\rho s$.

We should test if the synchronization of cycles is significant between the indicators and the reference cycle. A simple way to do so is the t-test for $H O: \rho s=0$.

Standard $t$-statistics is based on OLS regression. We use the Newey-West heteroskedasticity and autocorrelation consistent (HAC) standard errors (lag truncation $=5$ ) to account for possible serial correlation and heteroskedasticity in errors et.

The synchronization of cycles among our chosen variables can be measured and tested based on the index of concordance between two paired specific cycles.

How many concordance indexes can we obtain? We have a total of 15 different cyclic variables (see the following chapter about the empirical data), which need to be paired provided they can be repeated according to the equation from combination theory as permutation with repetition:

Number of matches $=(n+r-1) ! / r !(n-1) !$

$$
\begin{aligned}
& \text { Where: } \\
& n=15 \text { cycle variables } \\
& r=2 \text { chosen numbers }
\end{aligned}
$$

Inclusion of the values in the equation gives 120 possible pairs which result in the concordance indexes $C_{x y}$, and the correlation coefficients $\rho$.

\section{Empirical Data and Analysis}

The data on the 15 time series which appear in the analysis relates to the time period between the years (and months) $1991 \mathrm{~m} 1$ and $2010 \mathrm{~m} 3$. Some time series are somewhat shorter and they start in 1992 or later, ending in $2010 \mathrm{~m} 4$ (see table 1.). As a result, while calculating concordance indexes of the two time series, the work technique was adjusted to the shorter time series. The data was taken from the Monthly Database on Central, East and South East Europe, which can be found on the following website: http://mdb.wiiw.ac.at/.

We use a uniquely comprehensive sample of monthly frequency data. Our data sets considered in this paper are monthly seasonally unadjusted data generated by the Croatian economy.

The variables we study are: the unemployment rate (UR); vacancy rate (VR); tourism arrivals (ARR); tourism overnight stays $(\mathrm{ON})$; real NB discount rate (RDR); the construction production index $(\mathrm{Cl})$; nominal narrow money (M1); the retail consumer price index (RPCl); industry production index (IND); productivity in industry index (PROD); nominal total import in Euro (IMP); nominal total export in Euro (EXP); nominal wage (WAGE); real wage (RW); real exchange rate (RE); nominal exchange rate (HRK).

While longer data sets are usually preferred for studies of data synchronization turning points, estimating only over the given period will be less susceptible to charges of regime change. When it comes to our data, the synchronization processes of the business cycles mainly coincide with the process of economic transition and start with the majority of large structural changes in the economy, politics and environment in the first half of the 90 s. 
Applying the dating rule described above with a minimum duration of the cycle of 9 months to the selected annualized growth rate time series for the various time span period from January 1990 to March 2010 yields the statistics displayed in Table 1. Expansion phases are under the heading TP (or PT in the case of unemployment) and recession phases under the heading PT.

Table 1 (in the appendix) presents the dating chronology and different turning points for the relevant time series, the annualized growth rate variable and its annualized growth rate cycles based on this procedure.

Figures 1-4 (in the appendix) illustrate the filtered year on year growth of industrial production and the construction index rate and their cycles graphically, showing their growth rate expansion and recession phases according to trended components. Because of the limited space in this paper we show only these figures and not the rest of the 26 graphs that refer to the remaining 13 time series variable.

On average, expansion in unemployment rates (or contraction in economic activity) is shorter and much weaker than expansion phases in vacancy rates. Also, unemployment displays a much stronger change in expansion than other variables, but a shorter average duration measured by conjectural phases and relatively long contraction phases. In general, asymmetries over cyclical phases are present in all series.

We do not intend to further quote Table 1's interpretation of the remaining introduced variables, but will below, concentrating on the synchronization aspect of Croatian business cycles.

We have tabulated the concordance measures and the test statistics in Tables 2 and 3. In the first part of Table 2, the concordance statistics Cxy 's are reported above the diagonal while the correlation coefficients $\rho$ 's are reported below the diagonal, and $\mu S$ and $\sigma S$ are given at the bottom.

In the second part of Table 2, standard t's are reported below the diagonal while the robust $t$ 's are reported above it. Some of these statistics significantly reject $\mathrm{HO}$. The large $t$-values (approximately above the value of 2 ) also suggest the existence of co-movement between the cycle and the reference cycle.

Our ad hoc criteria by rule of thumb for grading the synchronization strength between the two cycles of the paired variables according to the concordance index are:
- 0-0.25 very weak synchronization,

- 0.26-0.5 weak synchronization,

- 0.51-0.75 moderately strong,

- $0.76-1$ very strong.

Clearly, synchronization is only present in the case of a significant correlation coefficient, whose sign determines the direction of the mutual cycle movement of the two variables. In principle, in a weak or a very weak synchronization of the two cycles, the correlation coefficient is not significant even in the standard form.

\section{Results and Discussion}

In our discussion and analysis of the results, we will refer mainly to strong synchronization phenomenon such as paired cycles, and in that domain, we will have significant correlation coefficients according to the regressional equation (9) and the $t$-value.

Judging by the height of the concordance index from the aspect of unemployment, as a referent variable, it appears that the highest degree of cycle synchronization exists between the cyclic growth in unemployment and the cyclic decline in industrial production. The latter concordance index equals 0.75 , yet the associated correlation coefficient, which equals approximately 0.44 and which, although significant with application of both the $t$-statistic and the robust $t$-statistic, only gives the indication of an incomplete inter-temporal interdependency in movement. Towards the top of the moderately strong synchronization, there are movements between tourist arrivals and unemployment rates. This is not surprising as Croatia is, however, a tourist country with an abundance of employment potential for "nonvoluntarily unemployed persons".

How does the nature of unemployment cycles as part of business cycles vary across different phases of financial cycles?

The result of the pairing of the areas of the unemployment rate and a real discount rate (part of the financial cycle) can give us the appropriate answer. It appears that the instrument of the discounting interest rate is, (albeit in an interplay with domestic inflation trends) one with which the Croatian National Bank intervenes in the economy, be it by facilitating or aggravating the inflow of new loan funds for the economy, moderately strongly sychronized with unemployment. A common feature of these labor recessions in Croatia (from 2009 to 2010 and afterwards 
underlined) was that they were accompanied by various types of financial disruptions, including contractions in the supply of credit and declines in asset prices. The bursting of the housing bubble in the USA (during 2007) and the resulting financial crisis worldwide was followed by the worst output slowdown in Croatia since the early 1990s. In a very short period, after barely one year, the international financial crisis has spilled over with numerous negative effects to Croatia's financial and labor markets.

A moderately strong degree of synchronization exists between unemployment and the movement of the real exchange rate between the Croatian Kuna and the Euro (HRK/EURO) (as opposed to the nominal rate, where synchronization is of a weak intensity). In fact, a strong degree of coincidence exists between unemployment cyclic growth and the appreciation of the real Kuna exchange rate. Although the correlation coefficient is not high (it equals 0.28 ), this positive correlation is, however, significant, according to both concepts of measuring the t-values.

A very strong degree of synchronization of two paired cycles can be seen in the movement of the growth of the vacancy rate, i.e. the growth rate of tourist arrivals, as well as the growth rate of the vacancy rate and the growth rate of exports. In both cases, the concordance index is 0.8 , and the associated correlation coefficient, which is significant in both cases and considerable, suggests coinciding variables due to a pronounced co-movement of variables. It is clear that the rate of filling of vacant work positions grows in the same direction as the growth in tourist arrivals (in Croatia otherwise chronically problematic) and goods export.

A moderately strong degree of synchronization also exists between the vacancy rate and the rate of construction sector (the concordance index is 0.7 ); this is not surprising as the expansion of the construction sector is, in fact, closely associated with the expansion of employment, thus growth in construction is a pro-cyclical variable. It should be noted that the bubble bursting in the property market and the decline in the demand for flats during the last two years directly facilitated the decline in the employment rate in Croatia. The correlation coefficient, calculated as the regression coefficient, points to the mutual movement of the said variables, with a high significance for the correlation coefficient estimate. These negative occurrences, in Croatia are linked to the cause of the financial crises in the USA and the global world economy after 2008. During the pre-great recession period the Federal Reserve kept interest rates at historically low levels, which fueled housing demand (hence expansion of the housing price index) and encouraged lenders to relax mortgagelending criteria. The international financial crisis was precipitated by the bursting of the housing price bubble in America and increases in actual and expected mortgage defaults.

The cycles of tourist overnights, as a referent variable, were not paired with any other cycle in the form of a very strong mutual synchronistic cycle. Towards the top of the moderate synchronization, judging by the concordance indexes of these tourist cycles, are industrial production variables (0.7) and the variables of the construction industry (0.65). We presume that the strong degree of synchronization of the given phases of the tourist overnights and industry cycles, in the inter-temporal sense, is a consequence of a greater realization of the food and crude oil industries within a tourist season, as well as the expansion of construction investment, although the latter may only be a pure chance in coincidence. Moderately strong synchronization exists between cyclical phases of tourism (both from the aspect of overnights and total arrivals) and cyclic phases of import. As the correlation coefficient is not significant from the point of view of the robust t-value, it is inopportune to make conclusions on the simultaneous movement of imported goods due to the great import dependency of the Croatian tourist economy. A high degree of moderately strong synchronization also exists between the probability that a certain cyclic phase of tourist arrivals will coincide with the cyclic phase of goods export. The correlation coefficient is, in this case, significant. We do not have either a rational answer, or a theory that would explain this puzzle. Is this a question of coincidence, an increased delivery of built ships during the summer months, or something else?

The cyclic phase of the real discount rate's inclining trend is in the largest measure synchronized with the acceleration of inflation measured according to the RCPI. The high concordance index $(0.75)$, as a result of the pairing of these two areas, should not be surprising. The real discount rate is, in fact, a result of the nominal discount rate, reduced by the inflation percentage; apart from this, it is logical that in the inflation episodes, by instrument of discount rate operation, thus influencing the business banks' loan potential, the Croatian National Bank increases the loan price by increasing the discount rate, in order to reduce inflation pressures. It is clear that 
the Croatian National Bank uses this credit and monetary instrument very successfully for the purposes of antiinflation politics, but it is also clear that it is done in a predictable way, as the correlation coefficient is relatively high and highly significant among real discount rate and RCPI cycles. It seems that cycles of labor productivity, too, are rather strongly synchronized with the cycles of the real discount rate. Labor productivity in the circumstances of, say, more expensive money, is perhaps synchronized with the discount rate growth, due to the illusion of higher wages and the so-called wealth effect, with labor entropy measured by absenteeism degree thereby being reduced. In the latter case also, the regression parameter, which measures the correlation coefficient, is highly significant. It is interesting that the construction sector is, to a very large degree, synchronized with external trade trends to a larger measure with imports (concordance index 0.9) than with exports (concordance index 0.74). This is why it is not surprising that imports in 2009 and 2010 were slowed also as a consequence of the fall in conjunction with the construction industry. According to the Official Statistics Department of Croatia the GDP in 2009 decreased by about 5.8\%, and in 2010 about $2 \%$. The current recession (perhaps better put, depression) is specifically associated with financial disruption episodes in advanced economies (America and EU), notably housing price busts, and is longer and deeper than other recessions in Croatia's past.

Given that the construction sector is pro-cyclically directed compared to GDP trends, the revival of the construction sector will signify the exit from a very serious recession but also the revival of external trade flows, a larger fiscal income due to larger custom income, etc. The construction sector is moderately strongly synchronized also with cyclical inflation fluctuations. It appears that the increase of prices in the construction sector present in the observed period (the bubble price in the construction sector in pre-recession years before 2008) stimulates the strengthening of the offer in the flat construction sector, this further being reflected in the inflation of retail prices. The cyclic fluctuations of the construction sector are moderately strongly synchronized both with the movements of productivity and the industrial production movements. It should be emphasized that in all of the noted cases the correlation coefficients are high.

The cyclical movement of the monetary aggregate M1 is, as expected, considerably synchronized with the cycles of nominal foreign exchange rate of the Croatian Kuna
(HRK). Namely, the cyclical growth of M1 causes cyclical depreciation impulses in the Kuna. In the exercise of determination of the synchronization index RCPI, as a referential variable, the cyclical movement of retail prices is closely synchronized with the cyclical movement of labor productivity and imports (both correlation coefficients are significant, i.e. different from zero). Industrial production is very synchronized with the fluctuation of import movements; in this case, too, the correlation coefficient is significant. The cyclical movement of productivity is, to a considerable degree, synchronized with the movement of import and nominal wages. As imports represent an important input in the economy due to the high import dependency of the Croatian economy, imports in Croatia can act proactively from the aspect of productivity strengthening, but also from the aspect of nominal wages growth, provided that productivity also grows. In Croatia, import is, to a considerable degree, synchronized strictly with export movements, probably due to the domination of the reexport business, but also due to the import dependency of the export business.

Finally, it can be concluded that the complex of nominal and real wages, together with the Croatian Kuna's (HRK) exchange rate, is a highly inter-synchronized area of cyclic movement. Although the correlation coefficients are highly significant when it comes to the robust testing of the t-values, these findings are of a trivial nature and are of no surprise to us.

\section{Conclusions}

The hypothesis of this paper, that the results should lead us to some important stylized facts regarding business cycle dynamics in Croatia, has been proven.

Our regression exercise findings allowed us to identify significant correlation coefficients and concordance between the following business cycles in Croatia: first, stark co-movement exists between unemployment cycles and industrial production cycles. That result shows that there is a high level of probability that the dismissal of employees in the Croatian economy will coincide with a contraction phase in industry. This is the first stylized fact of Croatian business cycles. This abstracted result is a trivial novelty in itself, but could be a substantial contribution to Croatia's economic literature due to formal testing deduction. The implications of this result on the conceptualization and creation of the economic and developmental politics of the Republic of Croatia 
touch on normative economics. In order to amortize contraction shocks to the increase in unemployment, Croatian economic politics needs to create a new industrial policy.

The cyclic phase of growth of new job position openings coincides, in large measure, with the cyclic phase of growth of exports and construction, as well as with tourist arrivals. The latter finding is the second stylized fact of Croatian business cycles. In terms of novelty and scientific contributions to this result we emphasize the following: the job creation process, as a phenomenon in the labor market in Croatia's recent history, neglects the impulses coming from industry and are much more attracted by those coming from the service economy. The implication of this result on the formation and creation of economic and developmental policies is the need for a stronger proactive policy of strengthening service (tourism, construction) and export economics for the purposes of the creation of new work positions.

The third stylized fact derived from our statistical results and their contribution to economics literature is that there is an almost perfect synchronization between the cyclic phases of the construction industry and imports, and a somewhat a lesser one concerning exports. Thus the picture of the general economic recession adequately corresponds to that finding. It is very well known from the empirical findings that the construction sector, as the bearer of the so-called price bubble, works pronouncedly pro-cyclically during growth phases, but also vice versa. In our case, this is additionally aggravated by the decline in the external trade exchange, which occurs in synchronization with the construction contraction. The implications of this result on the conceptualization and creation of developmental policies of the Republic of Croatia are opposed. If a state wants to strengthen its budget revenue in a short period of time based on customs duties, it will support expansion of the construction sector, with occasional bubble surges, especially due to the nearing of Croatia's EU accession, and if on the other hand it wants to strengthen the industrial sector of the industry complementary to construction, it will have to opt for an import substitution strategy.

The estimation of the turning points from a relatively medium time run time series despite the monthly or high frequency intensity was a constraint in our research. Statistical data on the monthly basis of our time series are missing in the longer time span in Croatia. Thus, a relatively short time span is one of the major limitations of the data as well as our regression results.

In our opinion, it may be useful to further investigate the dichotomy between the lag and lead terms of two opposite cycles in calculating the concordance index or using an approach based on a different filter data, or synchronization methodology.

One step to improve and justify the success of our research in light of its results would be a more proactive anti-recession policy, both on the real side (the construction building sector, as well as tourism and industry) and the financial part of economy (injecting more money into the economy by dropping interest rates). [․

\section{References}

Aczel, A. D., 2004. Chance: A Guide to Gambling, Love, and the Stock Market, Thunder's Mouth Press.

Avouyi-Dovi, S., et al., 2006. Are Business and Credit Cycles Converging or Diverging? A Comparison of Poland, Hungary, the Czech Republic and the Euro Area, Banque de France, Working Paper NERE\#144.

Blanchard, O. J. and S. Fischer, 1989. Lectures on Macroeconomics, The MIT Press.

Bordo, Michael D., and Joseph G. Haubrich, 2010. "Credit Crises, Money and Contractions: A historical view," Journal of Monetary Economics, Vol.57, pp.1-18.

Bry, G. and C. Boschan, 1971. Cyclical Analysis of Economic Time Series: Selected Procedures and Computer Programs, NBER Technical Working Paper No. 20.

Burns, A. and W. Mitchell, 1946. Measuring business cycles, New York: NBER.

Canova, F., 2007. Methods for Applied Macroeconomic Research, Princeton University Press.

Claessens, Stijn, M. Ayhan Kose, and Marco E. Terrones, 2009. "What Happens During Recessions, Crunches, and Busts?" Economic Policy, October, pp. 653-700.

Claessens, Stijn, M. Ayhan Kose, and Marco E. Terrones, 2011. "Financial Cycles: What? How? When?" NBER International Seminar on Macroeconomics 2010. eds: Lucrezia Reichlin and Kenneth West, National Bureau of Economic Research, IMF Working Paper, No 11/76. Credit and Banking, Vol. 29, No. 1, February 1997.

Gilchrist, S. and E. Zakrajsek, 2009. "Linkages Between the Financial and Real Sectors: An Overview," Working Paper, Boston University

Gomez Biscarri, J. and H.F. Perez de Gracia, 2002. Bulls and Bears: Lessons from some European Countries. Working paper.

Harding, D. and A. Pagan, 2001. Dissecting the Cycle: A Methodological Investigation, Journal of Monetary Economics, 49(2), 365-381.

Hodrick, R. and E. Prescott, 1981. Post-war U.S. Business Cycles: An Empirical Investigation, Working Paper, Carnegie-Mellon, University. Reprinted in Journal of Money,

Juglar, C., 1862. Des Crises commerciales et leur retour periodique en France, en Angleterre, et aux Etats-Unis. Paris: Guillaumin. 
Lahiri, K., et al. 2003. Cycles in the Transportation Sector and the Aggregate Economy, University at Albany, SUNY, Department of Economics, Discussion Papers 03-14.

Lutz G. A., 2002. Business Cycle Theory, Oxford University Press.

Monthly Database on Central, East and Southeast Europe, http://mdb.wiiw.ac.at/
Reinhart, Carmen M., and Kenneth S. Rogoff, 2009. This Time is Different: Eight Centuries of Financial Folly, Princeton University Press.

Zhang, W. and J. Zhuang, 2002. Leading Indicators of Business Cycles in Malaysia and the Philippines, ERD WORKING PAPER SERIES NO. 32, Asian Development Bank.

\section{Appendix}

\begin{tabular}{|c|c|c|c|c|c|}
\hline $\begin{array}{l}\text { Variables/ } \\
\text { Estimation period }\end{array}$ & $\begin{array}{l}\text { Turning Point } \\
\text { (month) }\end{array}$ & & & & \\
\hline $\begin{array}{l}\text { Unemployment } \\
1991 \mathrm{~m} 1-2010 \mathrm{~m} 3\end{array}$ & $\begin{array}{l}T P \\
1995 \mathrm{~m} 61999 \mathrm{~m} 9 \\
2004 \mathrm{~m} 22005 \mathrm{~m} 4 \\
2007 \mathrm{~m} 5\end{array}$ & 39 & 32.5 & -10.056 & 8.568 \\
\hline $\begin{array}{l}\text { Vacancy rate } \\
1991 \mathrm{~m} 1-2010 \mathrm{~m} 3\end{array}$ & $\begin{array}{l}P \quad T \\
1993 \mathrm{~m} 41996 \mathrm{~m} 8 \\
2000 \mathrm{~m} 12003 \mathrm{~m} 1 \\
2007 \mathrm{~m} 5\end{array}$ & 38 & 46.5 & -17.270 & 18.662 \\
\hline $\begin{array}{l}\text { Tourism Arrivals } \\
1991 \mathrm{~m} 1-2010 \mathrm{~m} 3\end{array}$ & $\begin{array}{l}P \quad T \\
\text { 1995m3 1997m2 } \\
1998 \mathrm{~m} 5 \text { 2003m5 } \\
2007 \mathrm{~m} 1\end{array}$ & 41.5 & 29.5 & -30.255 & 5.926 \\
\hline $\begin{array}{l}\text { Overnight stays } \\
1991 \mathrm{~m} 1-2010 \mathrm{~m} 3\end{array}$ & $\begin{array}{l}\mathrm{P} \quad \mathrm{T} \\
1993 \mathrm{~m} 6 \quad 1994 \mathrm{~m} 11 \\
1997 \mathrm{~m} 61999 \mathrm{~m} 11 \\
2001 \mathrm{~m} 102004 \mathrm{~m} 8 \\
2007 \mathrm{~m} 8\end{array}$ & 26.6 & 30 & -2.271 & 2.253 \\
\hline $\begin{array}{l}\text { Real Discount Rate } \\
\text { 1993m1-2010m3 }\end{array}$ & $\begin{array}{l}\text { T P } \\
1995 \mathrm{~m} 61999 \mathrm{~m} 7 \\
2003 \mathrm{~m} 92007 \mathrm{~m} 9\end{array}$ & 50 & 48.5 & -2.484 & 1.298 \\
\hline $\begin{array}{l}\text { Construction } \\
1992 \mathrm{~m} 1-2010 \mathrm{~m} 1\end{array}$ & $\begin{array}{l}\mathrm{P} \quad \mathrm{T} \\
1992 \mathrm{~m} 8 \text { 1998m6 } \\
2001 \mathrm{~m} 62004 \mathrm{~m} 4 \\
2006 \mathrm{~m} 8\end{array}$ & 52 & 32 & -1.562 & 0.975 \\
\hline $\begin{array}{l}\text { M1 } \\
\text { 1992m12-2010m2 }\end{array}$ & 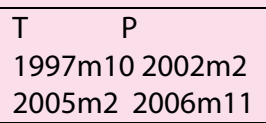 & 36 & 36.5 & -18.197 & 20.262 \\
\hline $\begin{array}{l}\text { RCPI } \\
\text { 1993m1-2010m3 }\end{array}$ & $\begin{array}{ll}T & P \\
1994 m 7 & 1998 m 7 \\
2002 m 1 & 2005 m 5 \\
2006 m 5 & 2007 m 5 \\
\end{array}$ & 27 & 33.3 & -0.25 & 2.563 \\
\hline $\begin{array}{l}\text { Industry } \\
\text { 1993m1-2010m3 }\end{array}$ & $\begin{array}{l}P \quad T \\
1996 \mathrm{~m} 111999 \mathrm{~m} 9 \\
2002 \mathrm{~m} 122004 \mathrm{~m} 3 \\
2006 \mathrm{~m} 3 \\
\end{array}$ & 24.5 & 31.5 & -1.928 & 1.883 \\
\hline $\begin{array}{l}\text { Productivity } \\
\text { 1994m1-2010m2 }\end{array}$ & 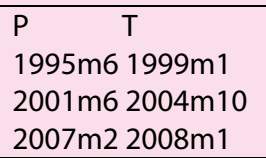 & 31.3 & 28.5 & -3.146 & 2.509 \\
\hline $\begin{array}{l}\text { Import } \\
\text { 1994m1-2010m3 }\end{array}$ & $\begin{array}{l}\mathrm{P} \quad \mathrm{T} \\
1994 \mathrm{~m} 101999 \mathrm{~m} 1 \\
2001 \mathrm{~m} 62004 \mathrm{~m} 2 \\
2006 \mathrm{~m} 4\end{array}$ & 41.5 & 27.5 & -20.7 & 7.257 \\
\hline $\begin{array}{l}\text { Export } \\
1994 m 1-2010 m 3\end{array}$ & $\begin{array}{l}\mathrm{P} \quad \mathrm{T} \\
1994 \mathrm{~m} 41997 \mathrm{~m} 7 \\
2000 \mathrm{~m} 72002 \mathrm{~m} 9 \\
2005 \mathrm{~m} 12 \\
\end{array}$ & 32.5 & 37.5 & -8.439 & 7.241 \\
\hline
\end{tabular}




\begin{tabular}{|c|c|c|c|c|c|}
\hline \multirow{2}{*}{$\begin{array}{l}\text { Variables/ } \\
\text { Estimation period } \\
\text { Nominal Wage } \\
\text { 1995m1-2010m3 }\end{array}$} & $\begin{array}{l}\text { Turning Point } \\
\text { (month) }\end{array}$ & \multicolumn{2}{|c|}{$\begin{array}{l}\text { Duration } \\
\text { (months) }\end{array}$} & \multicolumn{2}{|c|}{$\begin{array}{c}\text { Amplitude } \\
\text { (percentage) }\end{array}$} \\
\hline & $\begin{array}{ll}T & P \\
1997 m 3 & 1998 m 3 \\
2001 \mathrm{~m} 9 & 2004 \mathrm{~m} 4 \\
2005 \mathrm{~m} 6 & 2007 \mathrm{~m} 12\end{array}$ & 28 & 24.33 & -4.375 & 1.274 \\
\hline $\begin{array}{l}\text { Real Wage } \\
\text { 1995m1-2010m3 }\end{array}$ & $\begin{array}{ll}T & P \\
1997 m 4 & 1998 m 3 \\
2001 \mathrm{~m} 9 & 2002 \mathrm{~m} 12 \\
2005 \mathrm{~m} 6 & 2008 \mathrm{~m} 1 \\
\end{array}$ & 36 & 19 & -4.261 & 1.144 \\
\hline $\begin{array}{l}\text { Real exchange rate } \\
1994 m 2-2010 \mathrm{~m} 3\end{array}$ & $\begin{array}{l}P \\
P\end{array}$ & 19.5 & 24.6 & -0.42 & 0.50 \\
\hline $\begin{array}{l}\text { HRK/USA \$ } \\
\text { 1995m1-2010m4 }\end{array}$ & $\begin{array}{l}\mathrm{P} \quad \mathrm{T} \\
\text { 1997m8 1998m9 } \\
2000 \mathrm{~m} 22003 \mathrm{~m} 8 \\
2005 \mathrm{~m} 122007 \mathrm{~m} 9 \\
2009 \mathrm{~m} 5\end{array}$ & 25.33 & 21.66 & -12.864 & 10.627 \\
\hline
\end{tabular}

Source: calculated by authors

Table 1: Cyclical phases of variables

A. Concordance indexes and correlations of cycles among time series variables

\begin{tabular}{|c|c|c|c|c|c|c|c|c|c|c|c|c|c|c|c|c|}
\hline & UR & VR & ON & AR & INTR & CONI & M1 & RCPI & IND & PROD & IMP & EXP & RE & WA & RW & HRK \\
\hline UR & - & 0,52 & 0,65 & 0,66 & 0,7 & 0,54 & 0,41 & 0,54 & 0,75 & 0,62 & 0,62 & 0,5 & 0,64 & 0,29 & 0,36 & 0,28 \\
\hline VR & 0,02 & - & 0,59 & 0,75 & 0,16 & 0,7 & 0,37 & 0,34 & 0,34 & 0,42 & 0,58 & 0,8 & 0,54 & 0,36 & 0,45 & 0,59 \\
\hline ON & 0,29 & 0,18 & - & 0,58 & 0,23 & 0,65 & 0,41 & 0,43 & 0,7 & 0,58 & 0,61 & 0,38 & 0,39 & 0,28 & 0,48 & 0,52 \\
\hline AR & 0,31 & 0,51 & 0,17 & - & 0,33 & 0,55 & 0,14 & 0,35 & 0,55 & 0,54 & 0,66 & 0,68 & 0,51 & 0,28 & 0,32 & 0,54 \\
\hline INTR & 0,37 & $-0,68$ & $-0,27$ & $-0,31$ & - & 0,4 & 0,57 & 0,75 & 0,62 & 0,69 & 0,52 & 0,36 & 0,5 & 0,63 & 0,56 & 0,38 \\
\hline CONI & 0,11 & 0,37 & 0,31 & 0,07 & $-0,22$ & - & 0,16 & 0,68 & 0,59 & 0,64 & 0,9 & 0,74 & 0,42 & 0,6 & 0,51 & 0,53 \\
\hline M1 & $-0,19$ & $-0,27$ & $-0,21$ & 0,05 & 0,13 & $-0,7$ & - & 0,35 & 0,48 & 0,36 & 0,28 & 0,34 & 0,54 & 0,5 & 0,59 & 0,65 \\
\hline RCPI & 0,1 & $-0,33$ & $-0,14$ & $-0,29$ & 0,49 & 0,27 & $-0,42$ & - & 0,52 & 0,74 & 0,65 & 0,45 & 0,47 & 0,63 & 0,53 & 0,45 \\
\hline IND & 0,44 & $-3,2$ & 0,41 & 0,1 & 0,25 & 0,21 & $-0,05$ & 0,02 & - & 0,55 & 0,74 & 0,48 & 0,44 & 0,6 & 0,52 & 0,54 \\
\hline PROD & 0,23 & $-0,16$ & 0,15 & 0,08 & 0,36 & 0,4 & $-0,26$ & 0,47 & 0,11 & - & 0,75 & 0,44 & 0,56 & 0,67 & 0,58 & 0,52 \\
\hline IMP & 0,26 & 0,15 & 0,2 & 0,24 & 0,02 & 0,73 & $-0,42$ & 0,41 & 0,51 & 0,51 & - & 0,71 & 0,42 & 0,59 & 0,5 & 0,55 \\
\hline EXP & -0 & 0,59 & $-0,27$ & 0,32 & $-0,29$ & 0,42 & $-0,27$ & $-0,11$ & $-0,04$ & $-0,11$ & 0,33 & - & 0,56 & 0,44 & 0,53 & 0,57 \\
\hline RE & 0,28 & 0,09 & $-0,21$ & 0,05 & 3,22 & $-0,1$ & $-0,04$ & $-0,06$ & $-0,12$ & 0,11 & $-0,1$ & 0,08 & - & 0,42 & 0,5 & 0,45 \\
\hline WA & $-1,51$ & $-0,28$ & 0,12 & $-0,38$ & 0,2 & 0,26 & $-0,04$ & 0,26 & 0,21 & 0,35 & 0,23 & $-0,05$ & $-0,2$ & - & 0,91 & 0,69 \\
\hline RW & $-0,28$ & $-0,11$ & $-0,04$ & $-0,26$ & 0,16 & 0,14 & 0,12 & 0,12 & 0,06 & 0,18 & 0,17 & 0,13 & $-0,04$ & 0,78 & - & 0,7 \\
\hline HRK & $-0,43$ & 0,14 & 0,04 & 0,029 & $-0,26$ & 0,07 & 0,35 & $-0,09$ & 0,07 & 0,04 & 0,15 & 0,15 & $-0,01$ & 0,37 & 0,37 & - \\
\hline Mean & 0,571 & 0,523 & 0,512 & 0,466 & 0,518 & 0,328 & 0,645 & 0,531 & 0,531 & 0,518 & 0,33 & 0,41 & 0,6 & 0,6 & 0,687 & 0,534 \\
\hline STDEV & 0,494 & 0,498 & 0,399 & 0,499 & 0,499 & 0,469 & 0,477 & 0,478 & 0,488 & 0,499 & 0,47 & 0,491 & 0,489 & 0,49 & 0,463 & 0,499 \\
\hline
\end{tabular}

Note: Concordance indexes above the diagonal cells / correlations of cycles below the diagonal

Table 2 (A): Measuring and testing of synchronization of cycles 
B. Standard and robust t-statistics for $H O: \rho S=0$

\begin{tabular}{|c|c|c|c|c|c|c|c|c|c|c|c|c|c|c|c|c|}
\hline & UR & VR & ON & AR & INTR & CONI & M1 & RCPI & IND & PRO & IMP & EXP & RE & WA & RW & HRK \\
\hline UR & - & 0,22 & 4,54 & 5,07 & 5,74 & 1,6 & $-2,87$ & 0,56 & 6,95 & 3,3 & 3,52 & $-0,11$ & 4,06 & $-6,12$ & $-3,94$ & $-6,38$ \\
\hline VR & 0,01 & - & 2,75 & 8,97 & $-13,2$ & 5,91 & $-4,08$ & $-5,18$ & $-4,85$ & $-2,37$ & 2,14 & 9,92 & 1,22 & $-4,05$ & $-1,61$ & 1,99 \\
\hline ON & 2,09 & 1,23 & - & 2,62 & $-4,77$ & 4,65 & $-2,94$ & $-1,98$ & 6,38 & 2,13 & 2,78 & $-3,9$ & $-1,57$ & 1,56 & $-0,4$ & 0,63 \\
\hline AR & 2,32 & 4,16 & 1,22 & - & $-4,83$ & 1,08 & 0,74 & $-4,21$ & 1,5 & 1,08 & 3,64 & 4,97 & 0,78 & $-5,98$ & $-3,66$ & 2,6 \\
\hline INTR & 2,65 & $-6,66$ & $-1,9$ & $-2,18$ & - & $-2,8$ & 1,97 & 7,88 & 3,54 & 5,45 & 0,4 & $-4,23$ & 4,6 & 2,87 & 2,23 & $-3,34$ \\
\hline CONI & 0,75 & 2,81 & 2,86 & 0,48 & $-1,3$ & - & $-13,22$ & 4,04 & 3,3 & 5,43 & 14,8 & 6,46 & $-1,36$ & 3,76 & 1,99 & 0,95 \\
\hline M1 & $-1,32$ & $-1,86$ & $-1,37$ & 0,33 & 0,87 & $-6,6$ & - & $-4,85$ & $-0,84$ & $-3,64$ & $-6,4$ & $-4,08$ & 0,54 & $-0,65$ & 1,45 & 3,64 \\
\hline RCPI & 0,14 & $-2,67$ & $-0,93$ & $-2,02$ & 3,66 & 2,02 & $-2,81$ & - & 0,42 & 7,5 & 4,66 & $-1,61$ & $-0,8$ & 3,65 & 0,83 & $-1,24$ \\
\hline IND & 3,44 & $-2,2$ & 3,06 & 0,69 & 1,67 & 1,56 & $-0,42$ & 0,19 & - & 1,51 & 7,72 & $-0,66$ & $-1,8$ & 2,87 & 0,97 & 1,01 \\
\hline PROD & 1,51 & $-1,1$ & 1,02 & 0,53 & 2,56 & 3,04 & $-1,75$ & 3,32 & 0,69 & - & 8,19 & $-1,66$ & 1,69 & 4,96 & 2,44 & 0,54 \\
\hline IMP & 1,59 & 0,98 & 1,3 & 1,61 & 0,18 & 7,06 & $-2,8$ & 2,16 & 4,12 & 3,82 & - & 5,73 & $-1,66$ & 3,35 & 2,67 & 1,89 \\
\hline EXP & $-0,06$ & 5,11 & $-1,82$ & 2,27 & $-1,99$ & 2,98 & $-1,98$ & $-0,71$ & $-0,25$ & $-0,76$ & 2,72 & - & 1,18 & $-1,12$ & 1,97 & 2,1 \\
\hline RE & 1,9 & 0,57 & $-2,98$ & 0,37 & 2,22 & $-0,62$ & 0,26 & $-0,37$ & $-0,67$ & 0,77 & $-0,7$ & 0,67 & - & $-2,8$ & $-1,05$ & $-1,5$ \\
\hline WA & $-2,96$ & $-1,94$ & 0,78 & $-2,75$ & 1,32 & 1,82 & $-0,31$ & 1,67 & 1,39 & 2,45 & 1,69 & $-0,43$ & $-1,4$ & - & 18,8 & 5,52 \\
\hline RW & $-1,9$ & $-0,76$ & $-0,2$ & $-1,66$ & 1,1 & 0,98 & 0,65 & 0,67 & 0,52 & 1,16 & 0,98 & 0,95 & $-0,54$ & 6,98 & - & 6,57 \\
\hline HRK & $-3,18$ & 0,94 & 0,25 & 1,29 & $-1,43$ & 0,45 & 1,74 & $-0,56$ & 0,47 & 0,25 & 0,92 & 0,87 & $-0,67$ & 2,8 & 3,34 & - \\
\hline
\end{tabular}

Source: calculated by authors

Note: Standard t-statistics above the diagonal cells / robust t-value below the diagonal cells.

Table 2 (B): Measuring and testing of synchronization of cycles 


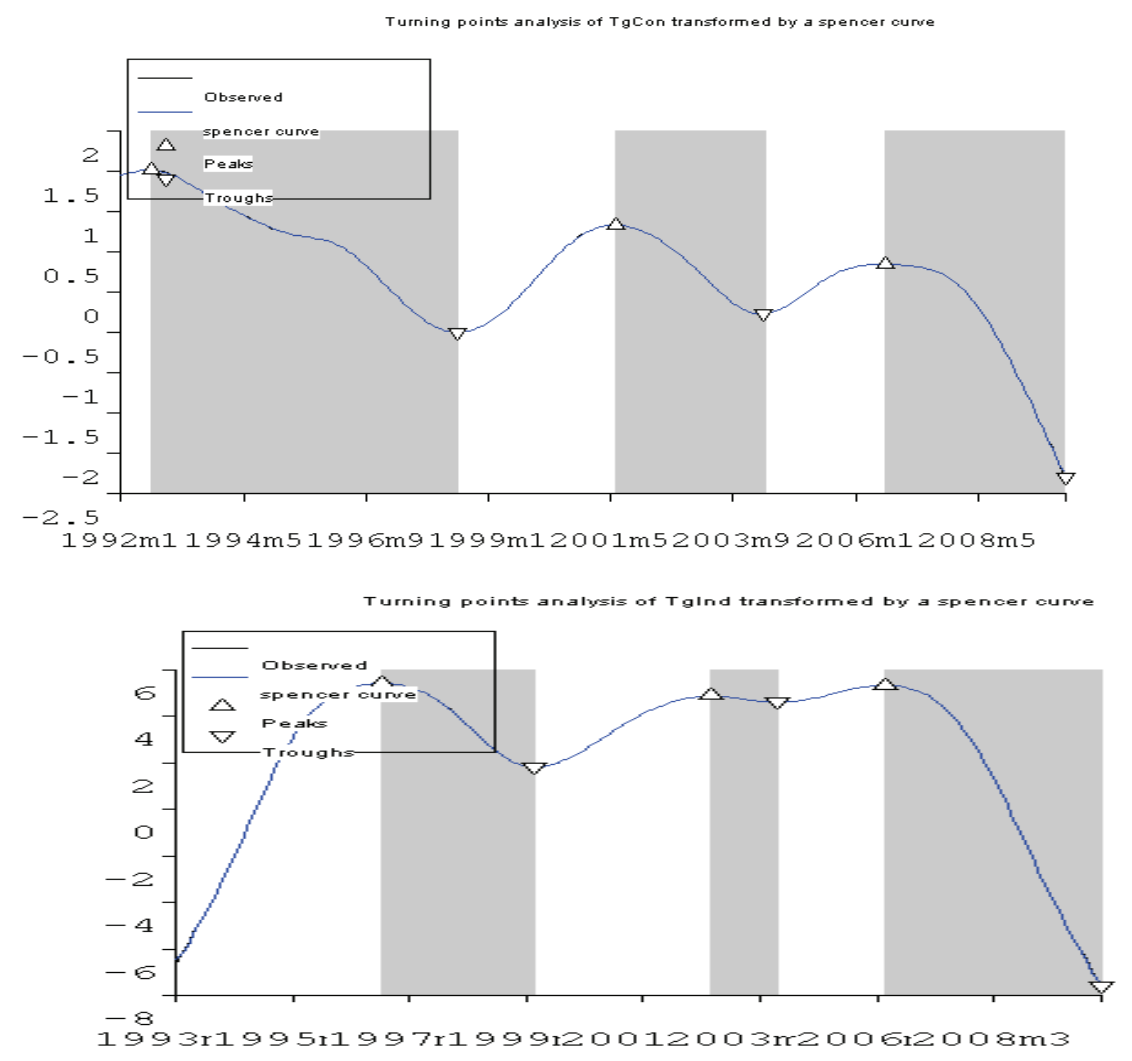

Figure 1-2: Turning points of trended growth rate on annual basis of Construction and Industrial Production Index
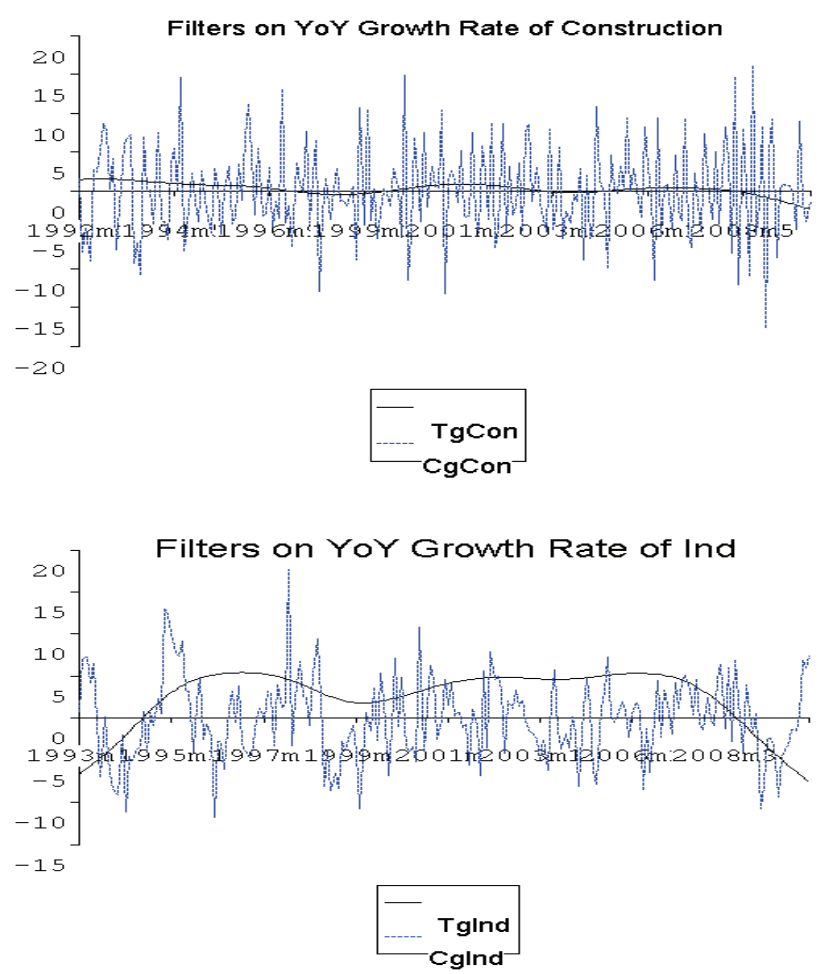

Figure 3-4: Trend and cycle of growth rate on annual basis of Construction and Industrial Production index 